\title{
How digitalization affects insurance companies: overview and use cases of digital technologies
}

\author{
Christian Eckert • Katrin Osterrieder (iD
}

Published online: 1 October 2020

(C) The Author(s) 2020

\begin{abstract}
The digital transformation is of increasing relevance for insurance companies' business models. It leads to opportunities as well as challenges, especially for IT departments as core enablers or preventers. Against this background, the aim of this paper is to provide a comprehensive overview of digital technologies (e.g., artificial intelligence, cloud computing) and the resulting use cases for the insurance industry. To this end, we conduct a review of academic articles, industry studies and publications of the supervisory authorities. We point to the resulting requirements for an insurer's IT and find many interdependencies between the digital technologies. Our results therefore emphasize the importance of a holistic digital strategy.
\end{abstract}

Zusammenfassung Die digitale Transformation ist auch in der Versicherungswirtschaft von höchster Relevanz und bietet Versicherungsunternehmen vielfältige Chancen, stellt aber auch zahlreiche Herausforderungen. Insbesondere die IT von Versicherungsunternehmen nimmt hierbei eine zentrale Rolle ein. Die Zielsetzung des vorliegenden Beitrags liegt in der Darstellung und Analyse digitaler Technologien wie beispielsweise Künstlicher Intelligenz oder Cloud Computing. Basierend auf einer umfassenden Aufarbeitung akademischer sowie praxisorientierter Literatur werden die dazugehörigen Anwendungsfälle für Versicherer identifiziert. Darüber hinaus werden die veränderten Anforderungen an die IT der Versicherungsunternehmen diskutiert. Aufgrund der zahlreichen Interdependenzen bei der Implementierung der digitalen Technologien begründet der Beitrag die Relevanz einer holistischen, digitalen Strategie für Versicherungsunternehmen.

C. Eckert $\cdot$ K. Osterrieder $(\bowtie)$

School of Business, Economics and Society, Friedrich-Alexander University Erlangen-Nürnberg (FAU), Lange Gasse 20, 90403 Nuremberg, Germany

E-Mail: katrin.osterrieder@fau.de 


\section{Introduction}

Innovation through digital technologies, platforms and infrastructures provides entrepreneurial opportunities across all industries and is reflected by new products, services and enhanced processes (e.g., Gault 2018; Nambisan et al. 2019). With regard to the insurance sector, innovation is strongly interrelated with the emerging technologies and concerns the entire value chain (e.g., Bohnert et al. 2019; Eling and Lehmann 2018).

The specific impact of the "digital transformation" through selected technologies for the insurance value chain has been discussed before (e.g., Bramblet et al. 2019; Eling and Lehmann 2018; Naujoks et al. 2017). However, academic as well as practitioner-oriented research lacks a comprehensive overview of the benefits and the opportunities for major technologies with associated insurance use cases and (technical) requirements for the IT in insurance companies.

Academic attention has been given to digitalization in the insurance industry with a systematic overview of previous research on the implications to the insurance value chain and its impact on the insurability of risks (Eling and Lehmann 2018). Bohnert et al. (2019) investigate the positive impact of digital agendas in terms of holistic strategic approaches to the performance of insurance companies. The majority of further academic studies are limited to excerpts of digitalization in insurance and thus specific technologies, e.g., the internet of things with the application of wearables for life and health insurers (Spender et al. 2019) or usagebased insurance (e.g., Desyllas and Sako 2013; Huang and Meng 2019). Moreover, previous literature investigates the opportunities of applying big data (analytics) for insurers. For instance, Zhang et al. (2019) focus on benefits in customer relationship management, Owadally et al. (2019) employ a data mining approach to detect periodicity in the context of underwriting cycles, and Fang et al. (2016) apply big data to better predict customer profitability. Gatteschi et al. (2018) contribute with an investigation of strengths, weaknesses, opportunities and threats when applying blockchain as distributed ledger technology for smart insurance contracts.

In this paper, we aim to contribute to previous literature by comprehensively analyzing the major technologies: big data, artificial intelligence, the internet of things, cloud computing, and the distributed ledger technology. These are all of current and future relevance for insurers. We comprehensively describe their functionalities, and emphasize the benefits as well as the opportunities for the insurers. Employing the digital technologies leads to specific insurance use cases, which reflect digitalization in the insurance industry. Identifying and analyzing them enables a better assessment of the value of digitalization for the insurers (e.g., Deloitte 2017). That is also why we comprehensively review the academic and practitioner-oriented literature to describe the related insurance use cases. Based on this, we identify specific requirements for an insurer's IT that arise when implementing the different technologies. We also consider interdependencies between them and thus combine a businessrelated perspective with a technological perspective. Since we find a multitude of interdependencies, our results emphasize the need for a holistic digital transformation strategy that takes a comprehensive perspective on the benefits, the use cases and the requirements for the IT as a result of a bundle of different digital technologies. 
The remainder of this article is structured as follows. Section 2 provides an overview of the major digital technologies and includes subsections to define and describe each technology, to analyze the benefits and opportunities, to derive insurance use cases, and to explain the resulting requirements for the IT of the insurers. Section 3 discusses interdependencies and Section 4 summarizes the results.

\section{Relevant insurance use cases and requirements for an insurer's IT}

Overall, we construct a data sample of 102 articles, which result from key word searches ("digitalization" AND "insurance", "big data" AND "insurance", "artificial intelligence" AND "insurance", "internet of things" AND "insurance", "cloud computing" AND "insurance", "distributed ledger technology" AND "insurance", "blockchain" AND "insurance") in the databases Business Source Complete, EconLit Full Text, and ABI/INFORM Collection. ${ }^{1}$ We also incorporate the results of Google Scholar and Google searches to consider recent discussions of the practitioners as done, for example, by Gatzert and Osterrieder (2020). In addition, we review, assess and incorporate cited references.

We aim to further examine the impact of digitalization on the insurance industry and therefore refer to digitalization as a comprehensive trend (e.g., Gatzert and Osterrieder 2020) with a broad range of (amongst others) economic consequences and do not use the term digitization, which is often utilized for purely technical investigations (e.g., Eling and Lehmann 2018). In terms of digital technologies, we include big data, artificial intelligence, the internet of things, cloud computing and the distributed ledger technology with blockchain as a common form, and refer to these as major digital technologies (e.g., Eling and Lehmann 2018; Kotalakidis et al. 2016), which are defined and discussed in detail in the following subsections. Table 1 summarizes our main findings and comprehensively presents a description of the technologies for insurers. Furthermore, Table 1 explains the benefits as well as the opportunities for each technology and points to the specific insurance use cases. Based on that, we then derive and emphasize the resulting requirements for an insurer's IT.

\footnotetext{
1 The selection of journal databases is based on the structured literature review by Eling and Lehmann (2018). The database Business Source Complete is a scholarly business database. EconLit Full Text includes articles in the fields of (amongst others) economics, including capital markets, country studies, econometrics, economic forecasting, environmental economics, government regulations, labor economics, monetary theory, and urban economics. Moreover, the journal database ABI/INFORM Collection incorporates further full-text journals, but also dissertations, working papers, as well as key business periodicals and allows us to investigate the latest business trends, which are especially relevant in the light of current insurance use cases. Note, that a detailed description of the databases Business Source Complete and EconLit Full Text is available at https://www.ebsco.com/products/research-databases?search= (accessed 04 August 2020), while the journal database ABI/INFORM Collection provides a detailed description at https://about.proquest.com/products-services/abi_inform_complete.html (accessed 04 August 2020).
} 


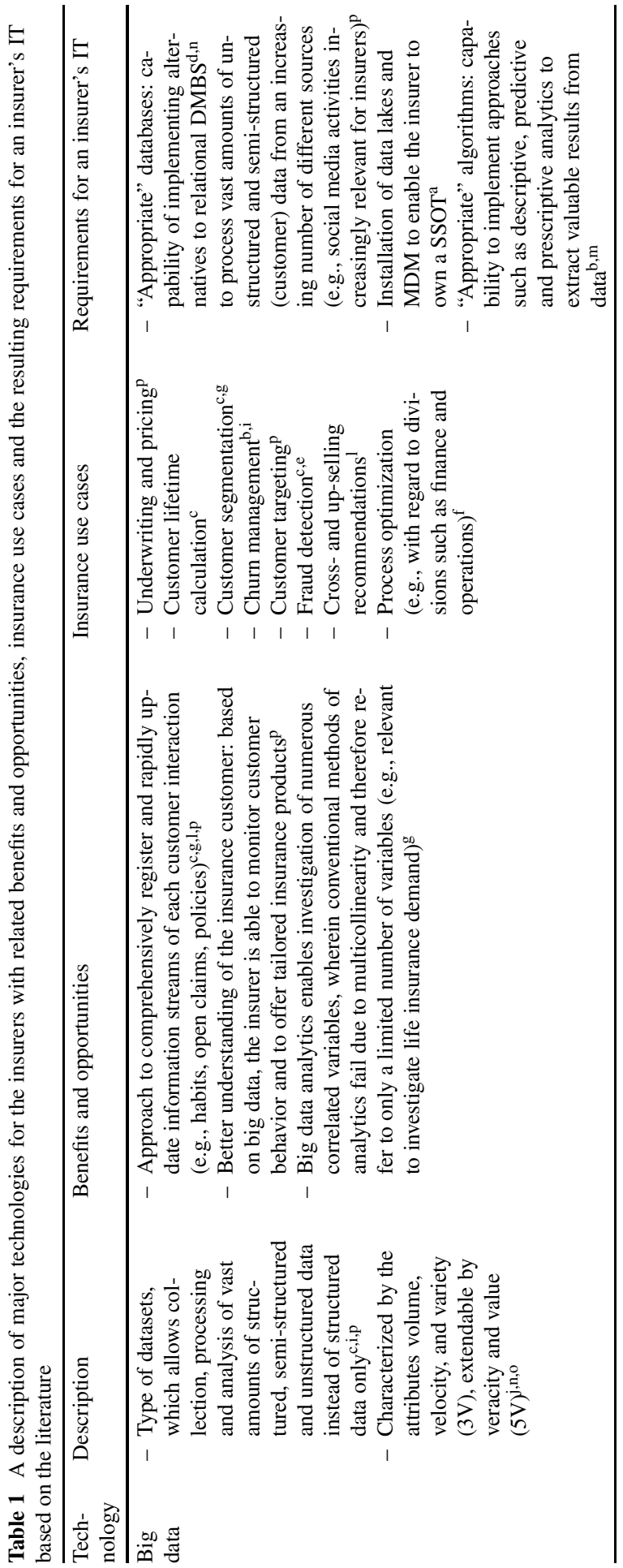




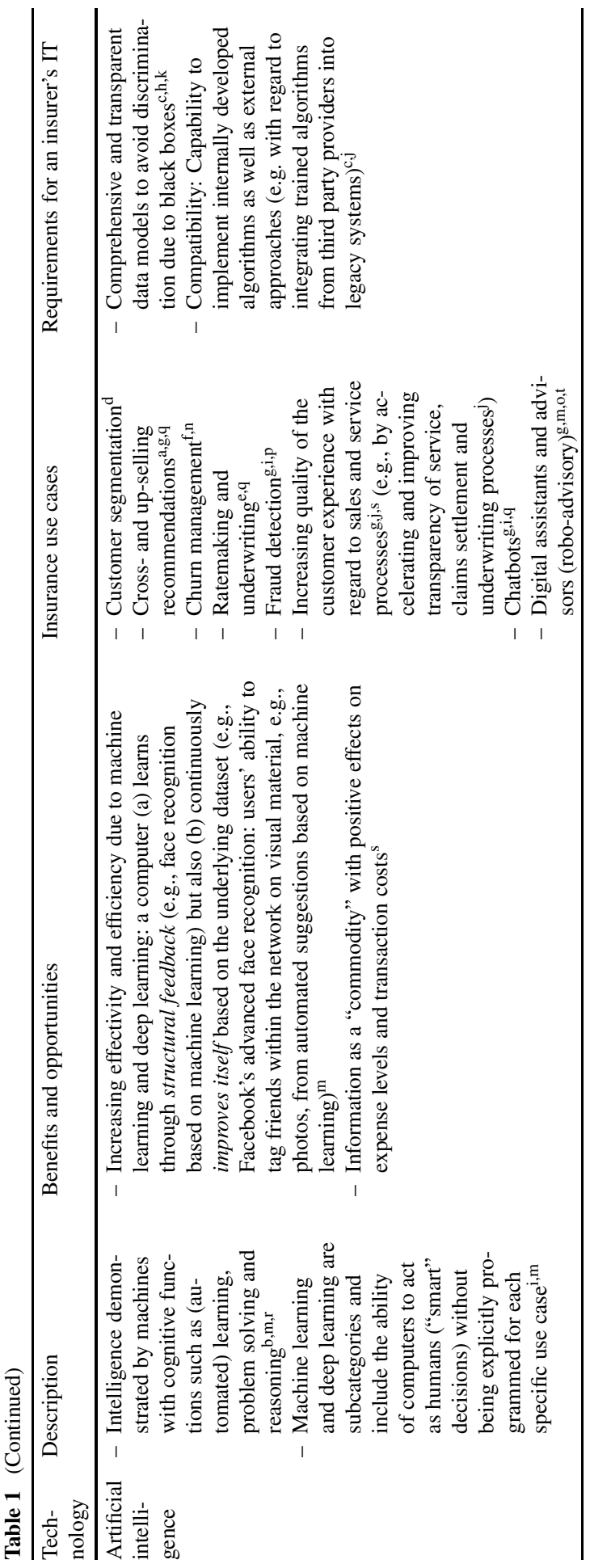




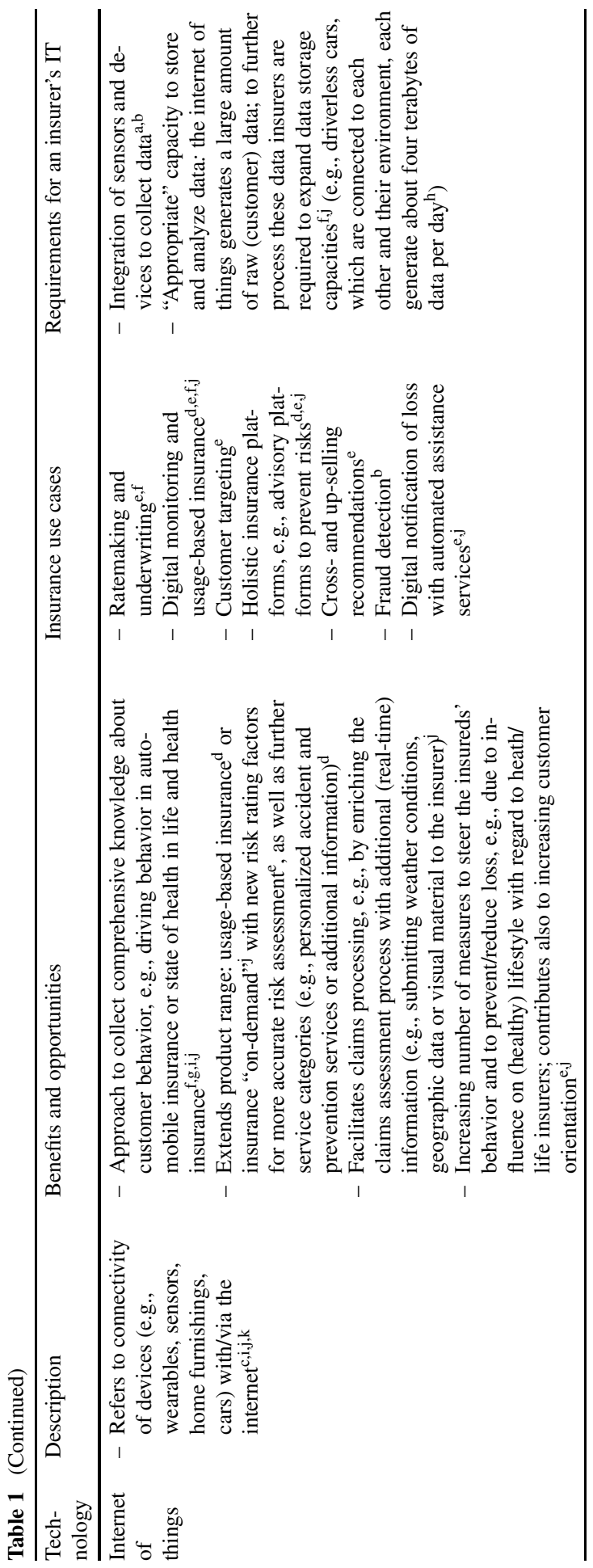




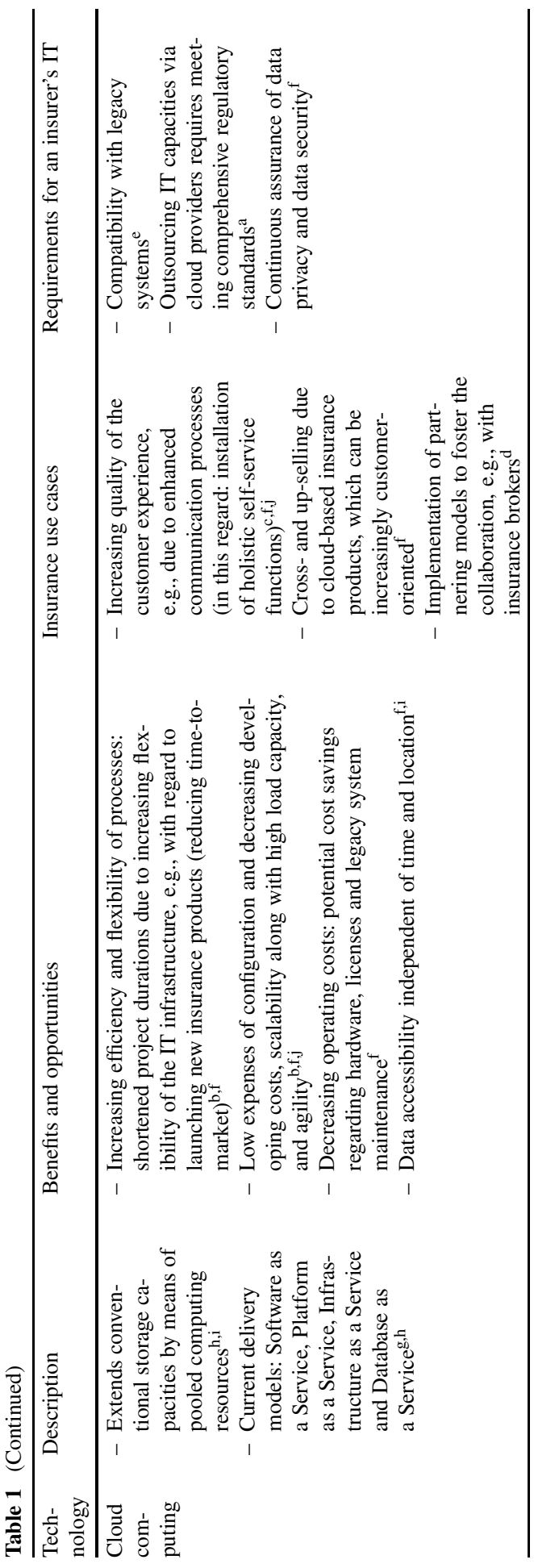




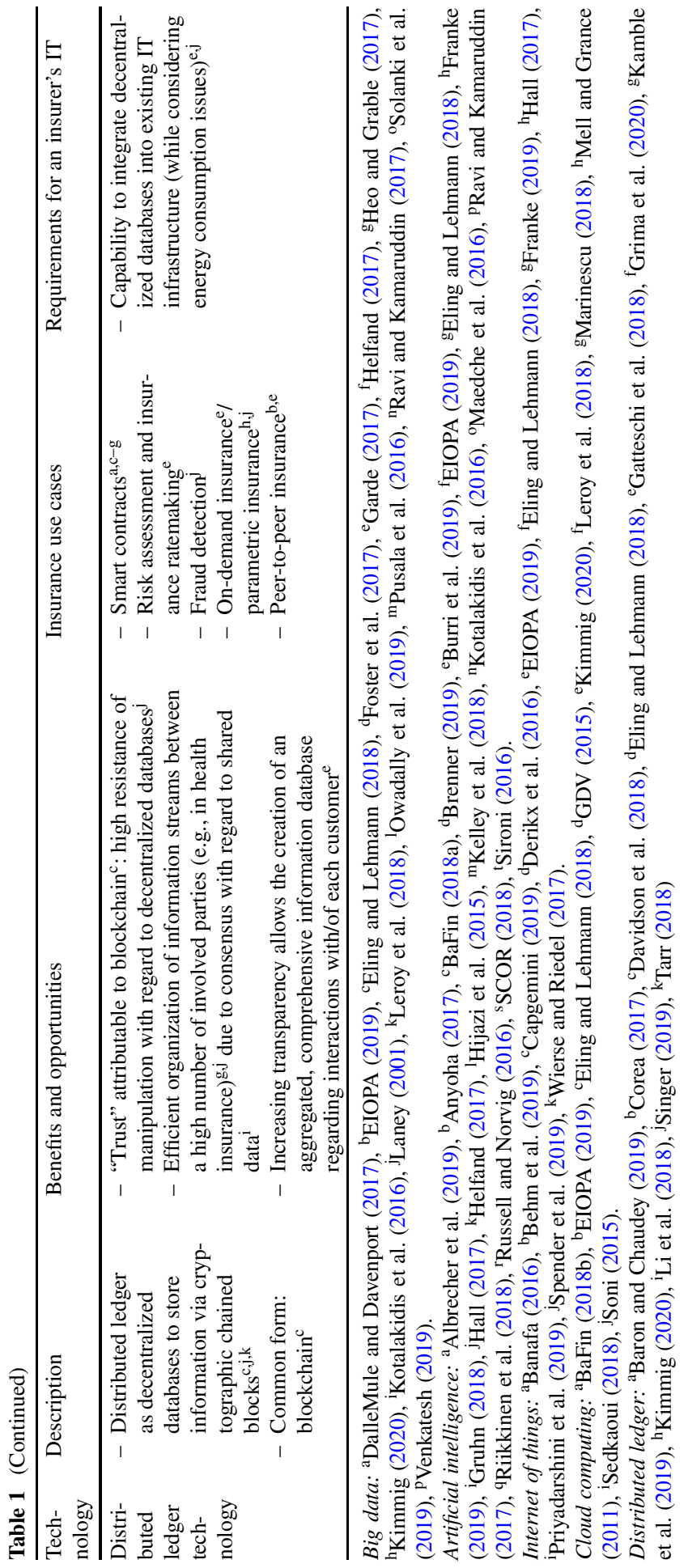




\subsection{Big data}

\subsubsection{Description}

While De Mauro et al. (2016) conclude that there is no single definition for big data due to its broad utilization, the term usually refers to a specific type of multidimensional datasets and is commonly attributed to " $3 \mathrm{~V}$ ": volume, velocity, and variety (Laney 2001; Owadally et al. 2019). Volume is assigned to the size of data, while velocity indicates the pace of data being generated and further processed. Variety focuses on the diversity of data, which can be structured, semi-structured or unstructured (e.g., Taleb et al. 2018; Solanki et al. 2019). The attributes can be extended to " $5 \mathrm{~V}$ " by veracity and value, where veracity reflects the degree of reliability of the data and describes the accompanying uncertainty of the results (Ravi and Kamaruddin 2017). With regard to value, there may be ambiguity, latency or lack of traceability of data, reducing the data quality due to the large amount of structured, unstructured and partially structured data. Consequently, the data quality can hardly be controlled (Taleb et al. 2018). In general, value requires the transformation of information into insights to realize economic value for the company and society (De Mauro et al. 2016). ${ }^{2}$

\subsubsection{Benefits and opportunities for insurers}

The relevance of big data for insurers is substantiated by the functionalities to collect, process and analyze large amounts of (customer) data (e.g., Eling and Lehmann 2018; Kotalakidis et al. 2016). This is fundamental for generating valuable insight from semi-structured and unstructured data stemming from different sources such as social media (e.g., Owadally et al. 2019; Venkatesh 2019). ${ }^{3}$ Thus, big data fosters a better understanding of the customers due to the accessibility of a comprehensive pool of information, which can refer to the interactions between insurer and customer, e.g., during a claims process, but also to the general behavior of a customer, e.g., when driving a car or with regard to sports activities or specific individual habits (Eling and Lehmann 2018; Heo and Grable 2017; Venkatesh 2019). Moreover, analytics approaches convert big data to understandable results for the insurers, e.g., by explaining how customers make their buying decisions. Big data (analytics) enables a high number of correlated variables to be investigated, wherein conventional methods of analytics fail (e.g., Heo and Grable 2017).

\footnotetext{
${ }^{2}$ Note that, e.g., Priyadarshini et al. (2019) and Sedkaoui (2018) add further characteristics such as variability, validity, vulnerability, volatility or visualization.

${ }^{3}$ To benefit from a comprehensive understanding of the customer, social media activities become increasingly relevant for insurers. For instance, twitter generates 12 terabytes of data per day as of 2019 (Venkatesh 2019).
} 


\subsubsection{Insurance use cases}

From these benefits and opportunities of big data, various use cases can be derived for the insurance industry (e.g., Eling and Lehmann 2018; Garde 2017; Helfand 2017; Heo and Grable 2017; Owadally et al. 2019). ${ }^{4}$ Big data is thereby capable of improving the insurance product at its core since integrating the technology to the risk assessment process can improve precise ratemaking and underwriting (e.g., Eling and Lehmann 2018; Venkatesh 2019). Due to the increasing availability of data around a customer, big data might lead to new risk factors and creates business opportunities in the fields of telematics referring to usage and behavior-based pricing (Eling and Lehmann 2018). Continually extending the information base about the customer allows insurance companies to more precisely differentiate several customer segments and positively affects customer lifetime value calculations (Eling and Lehmann 2018; Fang et al. 2016). Kotalakidis et al. (2016) additionally refer to the use case of a more precise prediction of lapse probabilities, which enables insurers to benefit from advanced churn management. However, knowing a policyholder also facilitates tailoring products and services to the customer, e.g., by customized cross- and up-selling recommendations or by delimiting the specific target groups for each product (Venkatesh 2019). Moreover, using big data in combination with related analytics approaches, e.g., text mining, allows the insurers to enhance claims assessments by better identifying fraudulent claims patterns (Eling and Lehmann 2018; Garde 2017).

Managing information streams within an own insurance organization is also subject to big data. Business units such as finance and operations can employ big data to deliver information for investment decisions or to process and analyze internal data more efficiently (e.g., performance data to analyze internal productivity), which is relevant to increase operational excellence (Eling and Lehmann 2018; Helfand 2017). Moreover, controlling products and insured risks can benefit from the vast amount of data as well as the general management of insurance companies since decisionmaking can be based on a more profound database (Naujoks et al. 2017). In this context, advanced management support systems and business intelligence can improve factors such as the calculation and monitoring of key performance indicators. Furthermore, the technology allows more advanced analyses in risk management. Practical examples refer to managing reserves, calculating large losses (e.g., in the event of a catastrophe), solvency predictions in the context of stress tests and own risk and solvency assessments (ORSA) (Helfand 2017).

\subsubsection{Resulting requirements for an insurer's IT}

For the efficient archiving, administration and analysis of large amounts of structured data, relational database management systems (DBMS) have been available for quite some time. These are based on the database language Structured Query Language

\footnotetext{
4 According to Bitkom and KPMG (2016) $46 \%$ of German insurers have a big data strategy, while only $26 \%$ are using big data analytics (Eling and Lehmann 2018) with applications most often in automobile or health insurance (BaFin 2018a).
} 
(SQL) (Foster et al. 2017). With regard to big data, relational DBMS fail due to their size and diversity (Ravi and Kamaruddin 2017). For a large number of unstructured data Not only SQL (NoSQL) databases can be preferred. ${ }^{5}$ NoSQL databases do not have a relational approach, but are compatible with relational DBMS and combine conventional statistical packages (Foster et al. 2017).

Given the main functionality of big data to collect and process vast amounts of data, the requirements for an insurer's IT include the installation of data lakes and master data management (MDM), which enable insurers to own a single source of truth (SSOT) (DalleMule and Davenport 2017). Data lakes collect data from multiple sources and store data in their original format, which is in contrast to data warehouses (e.g., Wibowo et al. 2017). Data lakes are therefore also able to store unstructured data, which is not possible in relational data systems of data warehouses. Hence, data lakes are not only especially useful to avoid data silos, but also offer an increasing number of efficient possibilities to find patterns and correlations in data (Stein and Morrison 2014; Zies and Schmid 2016). ${ }^{6}$

To comprehensively interpret big data, insurers are required to work with big data analytics and its subcategories descriptive, predictive and prescriptive analytics (Pusala et al. 2016; Sivarajah et al. 2017). ${ }^{7}$ Besides specific algorithms and databases, insurance companies have to gather knowledge and need appropriately skilled staff able to implement the respective big data tools, to monitor data quality, and to address the aforementioned requirements. Finally, the benefit of big data also depends on the availability, accuracy and reliability of the underlying data (EIOPA 2019). Hence, the preparation of data is a crucial step in order to gain useful information from the data. To be able to conduct holistic big data analyses, it is necessary to have a single data platform, where all data are stored, in contrast with data silos (BaFin 2018a).

\subsection{Artificial intelligence}

\subsubsection{Description}

Artificial intelligence can be defined as intelligence demonstrated by machines that mimics cognitive functions associated with the human mind, e.g., learning, problem

\footnotetext{
$580 \%$ of produced data are unstructured (Taleb et al. 2018).

${ }^{6}$ For instance, data lakes can be based on an Apache Hadoop architecture, which allows distributed and parallel big data processing (Stein and Morrison 2014). This enables insurance companies to increase data quality (Mathes 2016), which is crucial in big data.

${ }^{7}$ For instance, descriptive analytics deals with the question "What happened?" and focuses on the preparation of the data using descriptive statistics methods additionally including data mining tools (Sivarajah et al. 2017; Vesset 2018). The main objective is thereby to identify patterns and to visualize them (Pusala et al. 2016). While descriptive analytics focuses on historical data, predictive analytics uses them to provide forecasts and reveals the question "What will happen next?" (Vesset 2018). Predictive analytics contains machine learning techniques but also multiple linear regression models (Ur Rehman et al. 2016). Prescriptive analytics addresses the question "What should be done about it?" and proceeds predictive analysis results to automated recommendations using optimization and simulation techniques (Ravi and Kamaruddin 2017; Vesset 2018).
} 
solving and reasoning (Anyoha 2017; Kelley et al. 2018; Russell and Norvig 2016). ${ }^{8}$ Machine learning is an important subcategory of artificial intelligence (Eckert and Eckert 2020; Kelley et al. 2018). Algorithms use data to learn the transformation rules for generating a desired output by reducing the deviations between the generated and the desired result within an iterative training process (Deloitte 2017). ${ }^{9}$ While machine learning algorithms automatically improve through structural feedback, deep learning refines machine learning (e.g., Kelley et al. 2018) by using artificial neural networks (De Armond 2016; Eckert and Eckert 2020; Kelley et al. 2018).

\subsubsection{Benefits and opportunities}

One major opportunity of artificial intelligence for insurers refers to deriving the benefits of customer data along with big data (Kelley et al. 2018; Riikkinen et al. 2018). Implementing and integrating the corresponding algorithms into existing products and processes increases effectiveness and efficiency (Eling and Lehmann 2018). Assessing information by employing big data as well as further processing it with artificial intelligence implies information as a "commodity" of insurance companies, which substantiates the potential to significantly lower expenses and transaction costs. Artificial intelligence is generally highlighted as technology to further handle analytical results about insureds and to generate insight in terms of (ex-ante) risk prediction and (ex-post) risk monitoring (SCOR 2018). ${ }^{10}$

\subsubsection{Insurance use cases}

Artificial intelligence allows insurers to improve customer segmentation by means of pattern recognition compared to conventional approaches, e.g., by removing human bias, by finding hidden patterns, by providing automated updates based on individual behavior, or by defining personalized micro-segments. The resulting customer segmentation approaches are therefore characterized by high scalability with less intense maintenance (Brenner 2019). Based on customer segmentation, the technology further supports the insurance company by providing predictive analytics tools such as Extreme Gradient Boosting techniques to calculate lapse rates, churn propensities or to derive up- and cross-selling recommendations (Albrecher et al. 2019; EIOPA

\footnotetext{
${ }^{8}$ Currently, only applied artificial intelligence is available, which does not aim to apply intelligence to any problem, but focuses on a narrow task and therefore stands in contrast to artificial general intelligence (Gruhn 2018).

9 Machine learning algorithms in insurance can be trained by supervised learning, unsupervised learning or reinforcement learning. Moreover, artificial intelligence can be also integrated into insurance processes/ products by applying pre-trained models, e.g., in the fields of speech recognition, detection of sentiments, natural language processing and text analysis, anomaly detection, decision management, object detection, natural language generation, object detection or biometrics (e.g., Deloitte 2017).

${ }^{10}$ It is thereby necessary to make use of synergies with further technologies such as big data (Brenner 2019; Kelley et al. 2018): artificial intelligence extends the analyses by intelligently exploring large amounts of data with powerful algorithms to automate repetitive tasks and gain new predictive analysis knowledge (Deloitte 2017).
} 
2019; Riikkinen et al. 2018). Along with the use cases of big data, artificial intelligence can also be used in insurance ratemaking and underwriting (e.g., Riikkinen et al. 2018; Burri et al. 2019). Compared to conventional pricing methods, applying pattern recognition can, for example, result in more precise risk factors (e.g., Burri et al. 2019). Moreover, artificial intelligence improves the opportunities to detect fraudulent claims (Eling and Lehmann 2018; Gruhn 2018). For instance, insurers can utilize anomaly and image recognition mechanisms, which can also incorporate information stemming from external databases, to reliably detect insurance fraud (Gruhn 2018). ${ }^{11}$ Automated claims assessment processes can incorporate information about the behavior of insureds and of individuals within their social (media) networks or third parties, who are affected by the reported damage, or can square historical claims with the reported claims and consider fraudulent patterns (Ravi and Kamaruddin 2017). ${ }^{12}$

While those insurance use cases can be basically developed by analyzing big data, the potential of artificial intelligence can also be applied to increase the quality of the insurance customer experience, e.g., due to advanced services and fast processes (e.g., Eling and Lehmann 2018; Hall 2017; SCOR 2018). Facial recognition simplifies authorization and may therefore increase customer satisfaction in sales and service processes, whilst image recognition in general can be used to automatically analyze images in claims management (e.g., Shang 2018) allowing an acceleration of respective processes. ${ }^{13}$ Similarly, emotion recognition also typically applies convolutional neural networks and enables insurance companies to assess the emotions of their customers, e.g., during a phone call (Hijazi et al. 2015). Insurers can thus evaluate a customer's feedback based on sentiment analysis, which helps to improve the interaction with the customer (EIOPA 2019).

With regard to customer interaction use cases, the reviewed articles refer to roboadvisory (e.g., Eling and Lehmann 2018; Kelley et al. 2018; Maedche et al. 2016; Sironi 2016), which provides an automated, interactive, and intelligent process of advisory to the customer (e.g., Maedche et al. 2016; Sironi 2016). Currently, the term robo-advisor tends to refer to asset management user assistance (Kelley et al. 2018), but can also be transferred to fields such as healthcare (Jung et al. 2018). By integrating robo-advisors into insurance organizations, the digital assistant can rebalance portfolios with regard to asset management considering pre-defined risk appetites and in line with solvency requirements (Catlin et al. 2015; Eling and Lehmann 2018). In addition to robo-advisors, chatbots can digitally offer insurance products and services (e.g., Riikkinen et al. 2018). ${ }^{14}$ Chatbots are natural language

\footnotetext{
${ }^{11}$ Besides fraud pattern detection, image recognition enables insurers to estimate and verify claims sizes (Hijazi et al. 2015; Shang 2018).

12 The common outcome of these models assigns a specific probability to each claim, which allows conclusions about the presence of a fraudulent claim (e.g., Bhowmik 2011; Hassan and Abraham 2013).

13 According to the German Federal Government (2018) 34 of 550 German insurance companies use artificial intelligence to provide automated decision-making processes, whereas the implemented use cases focus on underwriting and claims processing.

${ }^{14}$ Chatbots are already more common in the insurance industry, since $42 \%$ of insurance companies make use of them (EIOPA 2019). According to EIOPA (2019) 2\% of insurance companies currently use roboadvisors, while further $25 \%$ are planning to do so.
} 
processing-based dialogue systems consisting of text input and output used in communication and customer care (e.g., Belanche et al. 2019; Abdul-Kader and Woods 2015; Hill et al. 2015). ${ }^{15}$

\subsubsection{Resulting requirements for an insurer's IT}

Supervised machine learning models are depicted as self-learning technology that needs to train and enhance its analysis capabilities over time (Hall 2017). Hence, it is necessary to provide the required data. Moreover, from a regulatory perspective, in Germany the BaFin (2018a) demands comprehensible and transparent models as well as a non-discriminatory data analysis. This is particularly challenging when using neural networks. Neural networks are often rather like black boxes, which is why further research regarding explainable and trustworthy artificial intelligence is necessary (BaFin 2018a). In addition, the IT infrastructure is continuously required to ensure data quality (e.g., resistance against manipulation) including the possibility to conduct internal revisions (BaFin 2019; SCOR 2018).

Moreover, by focusing on the functionalities of the application programming interfaces (APIs), insurance companies increasingly gain the ability to integrate, e.g., specific applications of artificial intelligence such as image recognition or external data from devices, which are related to the internet of things, as well as data stemming from brokers or members of partnering networks within holistic insurance ecosystems. APIs are therefore standardized interfaces that enable and simplify communication between different services (Spichale 2017). In the German insurance industry, BiPro and FRIDA, for example, provide APIs in order to achieve a more efficient data exchange.

\subsection{Internet of things}

\subsubsection{Description}

Due to the increasing integration of devices via the Internet (Wierse and Riedel 2017) along with the continuous adoption of smartphones, (connected) wearables, "smart" homes and cities, the internet of things becomes increasingly relevant (e.g., Capgemini 2019). The technology generally refers to an identifiable system of objects (e.g., furniture, wearables, vehicles) whose information is transmitted without human intervention, and has emerged in particular from the integration of microelectromechanical systems, wireless technologies and the Internet (Priyadarshini et al. 2019; Spender et al. 2019).

\subsubsection{Benefits and opportunities}

Integrating the opportunities through the internet of things helps to increase the interaction with the customer and extends the knowledge about the customer as an

15 "Intelligent" chatbots are trained based on historical customer interactions to automatically generate responses in text format (Riikkinen et al. 2018). 
individual. The connected devices can comprehensively collect information about the specific behavior of an individual customer and thus have the potential to support insurers in extending their product offerings with insurance "on demand" or in offering insurance products with the value proposition of additional services (e.g., Behm et al. 2019; Eling and Lehmann 2018; EIOPA 2019; Franke 2019; Priyadarshini et al. 2019; Spender et al. 2019).

For instance, health and life insurers assign particular relevance to wearables such as fitness trackers, but also to medical devices or clothing, including shoes. Moreover, property and liability insurers can benefit from the information, for example, that is recorded and transmitted by the sensors of connected cars (Spender et al. 2019). ${ }^{16}$ The devices and the vast amount of related customer information in addition to conventional data (e.g., demographic information, exposure, and customer interaction history) substantiates the relevance of the internet of things for the insurers (e.g, Behm et al. 2019; EIOPA 2019). Insurers benefit from the increasing number of measures to monitor the behavior of the individual customers. Based on this, insurers can steer the individual behavior of insureds by providing the impetus to change habits, e.g., increasing health awareness by incentivizing desirable behavioral patterns (e.g., EIOPA 2019; Spender et al. 2019).

\subsubsection{Insurance use cases}

The internet of things and big data are major drivers of new products such as telematics and usage-based insurance (e.g., Eling and Lehmann 2018; Spender et al. 2019). ${ }^{17}$ In this context, insurance ratemaking is based on the specific behavior of an individual and thus results in a more accurate pricing (Derikx et al. 2016; EIOPA 2019). Behavior-related data enable insurance companies to conduct digital monitoring and, therefore, to improve loss prevention by offering preventative support for customers and to reduce losses (Behm et al. 2019; EIOPA 2019; Eling and Lehmann 2018). Hence, the internet of things allows insurance companies to increase the frequency of customer interaction, to enhance customer engagement and to extend their scope beyond the moment-of-truth (Spender et al. 2019). This is particularly rewarding when insurance companies partner with companies from other industries and build an ecosystem (Behm et al. 2019). For instance, by partnering with tech companies such as the providers of wearables, insurers can introduce related marketing initiatives, e.g., by offering price reduction for fitness trackers (e.g., Spender et al. 2019). ${ }^{18}$

Moreover, the internet of things helps insurance companies to automate their processes (e.g., an automated first notice of loss or an automated trouble report)

\footnotetext{
${ }^{16}$ The functionality of the technology is expected to further improve with the widespread adoption of 5G (Capgemini 2019).

17 Currently, insurance companies integrate the internet of things into products such as motor insurance (e.g., Allianz, HUK Coburg) or health insurance (e.g., Generali) (Eling and Lehmann 2018).

${ }^{18}$ In practice, Spender et al. (2019) refer to a Japanese Life insurer who offers FitBit fitness tracker for free in order to collect personal data and to deduct/recommend health-promoting measurements to the individual insured.
} 
and allows insurance companies to collect more data about customers. Due to the better understanding of the customers, insurers can improve fraud detection (Behm et al. 2019; EIOPA 2019). Finally, the internet of things might also increase data quality due to fewer manual processes and increased automation (e.g., Karkouch et al. 2016).

\subsubsection{Resulting requirements for an insurer's IT}

The technology requires the implementation and integration of specific sensors, which collect and transfer data (e.g., Banafa 2016). Assessing large amounts of raw customer data accompanies the internet of things and requires sufficient capacity and knowledge to translate the results into insurance products, e.g., by employing a data analytics tool (e.g., Spender et al. 2019) and substantiates the need for appropriate IT services. The large amount of transmitted data is also why insurers are required to increase data storage capacities with regard to their IT infrastructures (Eling and Lehmann 2018; Priyadarshini et al. 2019; Spender et al. 2019).

\subsection{Cloud computing}

\subsubsection{Description}

Cloud computing service providers offer external computing and storage capacities that enable flexible access to pooled computing resources such as networks, servers, storage capacities, or applications (e.g., Sedkaoui 2018). ${ }^{19}$ The technology incorporates the service delivery models Software as a Service (SaaS), Platform as a Service (PaaS), Infrastructure as a Service (IaaS), and Database as a Service (DBaaS) (e.g., Marinescu 2018). The service models differentiate between the provided services and capabilities (Mell and Grance 2011). Moreover, utilizing cloud computing can refer to private clouds, community clouds, public clouds or hybrid clouds. Whilst a public cloud is open to the public, a private cloud infrastructure is operated by internal, company-owned data centers or a selected service provider and is exclusively accessible by a predefined target group. Community clouds are implemented by an extended circle of people with common interests. A hybrid cloud combines attributes of the two aforementioned cloud models (e.g., Leroy et al. 2018; Marinescu 2018; Mell and Grance 2011).

\subsubsection{Benefits and opportunities}

In general, the resulting computing resources facilitate a decline in management costs (e.g., Mell and Grance 2011). Due to on-demand payment schemes, cloud computing is a measure to increase cost effectiveness (e.g., Ali et al. 2015). Cloud computing allows insurers to increase their own flexibility as well as efficiency,

\footnotetext{
19 The definition of cloud computing incorporates the five attributes of an "on-demand self-service", "broad network access", "resource pooling", "rapid elasticity", and a "measured service" (Mell and Grance 2011, p. 2).
} 
since the required capacities can be rapidly scaled (BaFin 2018a; EIOPA 2019) ${ }^{20}$ For instance, the service delivery model IaaS includes renting storage capacities and computing power and allows insurers to reduce their own hardware capacities, which are required to be sufficient even at peak times. As a consequence, this kind of outsourcing enables insurance companies not only to save hardware and software costs but also leads to reduced expenses with respect to installation and maintenance. Moreover, SaaS can be applied to get standard software, services and applications of artificial intelligence with respect to, for example, image recognition or natural language processing from the cloud (e.g., BaFin 2018a). In addition to saving software development costs (e.g., Leroy et al. 2018), SaaS allows insurance companies to use the most up-to-date software (Kimmig 2020). In general, cloud computing enables access to data independent of time and location, which is especially relevant to the timely processing of data (e.g., large-scale data as a result of the internet of things) (Sedkaoui 2018), but also to a standardized IT infrastructure (Leroy et al. 2018).

\subsubsection{Insurance use cases}

A potential insurance use case of cloud computing is the comprehensive storage of contract information with accessibility for the customer, e.g., enabling self-service functions to real-time change documents (Eling and Lehmann 2018). Moreover, cloud computing provides the necessary infrastructure, to enable efficient information streams within an insurance organization and to consequently shorten implementation times of new or amended insurance products (Duncan et al. 2019). Cloud computing can thus contribute to a better customer experience, and can lead to enhanced cross-selling as well as up-selling opportunities (e.g., Leroy et al. 2018). Cloud computing is also discussed as an enabler for the integration of partnering models with regard to the collaboration with, e.g., industry partners, brokers or InsurTechs (e.g., the Trusted German Insurance Cloud from the GDV in Germany) (GDV 2015).

\subsubsection{Resulting requirements for an insurer's IT}

For insurance companies, it is necessary to integrate cloud computing into existing IT infrastructures (e.g., Kimmig 2020; Leroy et al. 2018). In this regard a lack of compatibility of legacy systems with cloud computing is often challenging (Urbach and Ahlemann 2016). In most cases, cloud and legacy applications have to interact in real time, which then requires, for example, an enterprise service bus (ESB). In an ideal situation, insurance companies should aim to replace legacy systems, which presents a major challenge (e.g., Kimmig 2020). The resulting IT landscape

\footnotetext{
20 According to the Lünendonk Study (2018), 39\% of the insurance companies have begun migrating parts of their IT infrastructure and applications to the cloud or getting new solutions from the cloud to create a single cross-domain collaboration database, whilst even $68 \%$ are considering moving legacy applications to the cloud (Duncan et al. 2019). Furthermore, according to Duncan et al. (2019) insurance companies aim to spend $11 \%$ of their IT budget in the next three years on cloud computing.
} 
is furthermore required to overcome data privacy and data security concerns in the context of cloud computing. Specific requirements are given by several regulatory frameworks (BaFin 2019).

\subsection{Distributed ledger technology}

\subsubsection{Description}

A distributed ledger is a decentralized database, which stores information complete and secure on distributed general ledgers via cryptographic chained blocks. The most common form of distributed ledger technology is the blockchain, which records forgery-proof transactions (e.g., data, contracts, record exchanges, identities). Powerful crypto-economic protocol-based incentive systems are used to authenticate a transaction in the database. This is also why "trust" is attributed to blockchain and the related transactions do not require any further approval of specific intermediaries (Davidson et al. 2018). ${ }^{21}$ This is done by algorithms that are executed by a large number of servers (nodes). After reaching consensus of the data sets, they are linked as a fixed block to the previous block with a timestamp, hash, and the transaction history (Tarr 2018). This is replicated at the same time from the network nodes of different owners at different locations (Singer 2019).

\subsubsection{Benefits and opportunities}

Due to the high resistance to manipulation, blockchain facilitates the secure exchange of data and is therefore discribed as technology to smooth internal processes as well as transactions with external partners (e.g., Grima et al. 2020). For instance, the veracity of a transaction can be confirmed without involving intermediaries such as public authorities or auditors. This is a major advantage of using blockchain (Davidson et al. 2018). Moreover, Singer (2019) emphasizes the opportunities to decentrally confirm specific (trigger) events utilizing algorithms. In a structured literature review, Kamble et al. (2019) outline the value of blockchain for health insurance. The health insurance sector is characterized by a high number of parties (e.g., patient, health care services, surgeries, pharmacies), which are affected by a claim (Kamble et al. 2019). By employing blockchain technology, information streams between these parties can be organized more efficiently due to the "trust" in exchanged data (Grima et al. 2020; Kamble et al. 2019; Singer 2019). As a consequence, successfully implementing blockchain technology can contribute towards increasingly transparent and fast processes, with the effect of reduced costs (Grima et al. 2020). Increasing the transparency of various interactions of a single customer with one or more insurers enables the creation of a comprehensive information database with respect to the interaction with a customer (e.g., Gatteschi et al. 2018). Even if there are still limitations to complex products such as Insurance Linked Securities (Albrecher et al. 2019), for instance, blockchain-based payment systems help to implement new insurance products (Gatteschi et al. 2018), which broaden

21 Blockchain is also discussed as "trustless consensus engine" (Davidson et al. 2018, p. 2). 
the range of product offerings and can help to strengthen the market position (Grima et al. 2020).

\subsubsection{Insurance use cases}

Blockchain has gained importance through cryptocurrency transactions, making it suitable for any form of immutable information storage, including smart contracts (e.g., Baron and Chaudey 2019; Eling and Lehmann 2018; Gatteschi et al. 2018; Grima et al. 2020; Kamble et al. 2019). The use case describes automated contracts, which pass their encoded conditions to the blockchain (Baron and Chaudey 2019). For instance, a smart contract can automatically authorize a payment due to the occurrence of predefined conditions (Grima et al. 2020), which can be the basis for insurers to settle claims in real-time (Kamble et al. 2019). ${ }^{22}$ The contract conditions are coded and transmitted to the blockchain, while oracles ${ }^{23}$ can be employed as third-party providers (Baron and Chaudey 2019). Moreover, authorized intermediaries (in this case insurance, law or medical firms) can bundle individuals' information on a consortium of blockchains and can thus integrate access for insurance companies (Gatteschi et al. 2018). By utilizing the accessible information, the distributed ledger technology enables increasingly automated underwriting as well as payouts, which can lead to a decrease in transaction costs. Further insurance use cases are discussed along with the trend of the sharing economy: the attributes of blockchain are especially suitable for microinsurance services, insurance on-demand as well as peer-to-peer insurance (Eling and Lehmann 2018; Gatteschi et al. 2018). However, Sheth and Subramanian (2019) emphasize the need to "appropriately" design insurance products. However, the opportunities of increasingly trusted certificates and also an enhanced identity management prevent and improve to detect insurance fraud (Gatteschi et al. 2018; Singer 2019). The insurance use case of fraud detection becomes especially attractive when combining the employment of blockchain with further technologies such as internet of things (e.g., incorporating data from connected cars to smart contracts) (Singer 2019). The combination of both also drives the implementation of parametric insurance (Kimmig 2020; Singer 2019).

\subsubsection{Requirements for an insurer's IT}

The technology generally requires the integration of decentralized databases with the existing infrastructure (Gatteschi et al. 2018; Grima et al. 2020; Singer, 2019).

\footnotetext{
22 According to PwC (2018) distributed ledger technology is not part in the strategy of $68 \%$ of German financial service providers and $46 \%$ think that it is not relevant or only slightly. However, to further develop and adapt the technology in the insurance industry, "B3i" was incorporated in 2018, owned by and dedicated to insurance companies. B3i aims to jointly develop new applications using distributed ledger for the insurance industry. Their first application is a catastrophe excess of loss product for reinsurance companies.

23 Oracles provide data or can also assume the role of a judicial authority; in the latter case, the thirdparty providers hold private keys and can sign transactions, which are triggered by externally verifiable conditions, e.g., environmental conditions (Berentsen and Schär 2017).
} 
Managing the IT therefore requires interdependencies with the internet of things to be considered. For instance, sensor data can be encrypted via blockchain and translated to (parametric) insurance products (e.g., Kimmig 2020). Moreover, applying blockchain requires the insurers to overcome issues of energy consumption and to assure privacy standards for all users, which is especially relevant in the light of automated codes that might attract hackers. This is why managing the IT of an insurance company also includes developing the related computer science skills to understand and further develop the code. Especially challenging with regard to distributed ledger and blockchain is the lack of standardization; the lack of a market-leading blockchain is a major barrier for widespread implementation within the insurance industry (Gatteschi et al. 2018).

\section{Discussion}

The presented technologies with the related insurance use cases comprehensively contribute to the digitalization of insurance business with opportunities, which might be increasingly important to competition. The insurance use cases can decrease claims costs and expenses, e.g., through automated claims handling, profitable underwriting with enhanced data usage and more effective fraud detection. Moreover, the insurers can enhance customer experience management along with improving customer satisfaction and customer retention (e.g., SCOR 2018). Further benefits refer also to strategic advantages through establishing new (innovative) insurance products (e.g., Dahuja 2019). While the status quo insurance business models build on recognizing damage and its indemnification, the presented digital technologies, with artificial intelligence at the forefront, allow new opportunities for prevention and for precisely predicting individual risks (Kelley et al. 2018). The major impact on the business models of the insurers results from the opportunities to generate data along with the new methods to analyze and assess them. The digital technologies can thereby help to address information asymmetries between the insurers and the policyholders, which are reflected by moral hazard and adverse selection (e.g., SCOR 2018). In contrast to other industries where digitalization affects nearly everything except the product, digitalization affects the core product of insurance companies. While the insurance business model is strongly focused on pure claims settlements (paying claims on time), insurers can employ, for instance, big data (analytics) to integrate customer centricity into their product strategy and thereby innovate their services (Lehrer et al. 2018).

However, to "appropriately" react to digitalization, insurers are forced to prioritize the use cases and to integrate them to their own strategy. In this context, insurance companies are especially challenged by taking into account the risk of delayed reactions to technological developments and the initial costs of the implementation (e.g., Pritchett et al. 2019; EIOPA 2019). When implementing the technologies, one main challenge is presented by legacy systems (e.g., BaFin 2018a). Legacy systems have comprehensively evolved over time and are assigned to a high degree of complexity (e.g., Urbach and Ahlemann 2016). However, employing all the technologies requires the integration and transformation of conventional informa- 
tion management systems towards a compatible IT architecture (e.g., Kimmig 2020; Venkatesh 2019; Zies and Schmid 2016). ${ }^{24}$ In this context, the findings in Sect. 2 show that the implementation of the major technologies with the insurance use cases comprehensively changes the requirements for the existing IT of the insurers. These changes are not limited to a single technology since the presented major technologies are highly interrelated. This substantiates the necessity to develop holistic strategic plans, which analyze, assess and prioritize the technologies with the multitude of resulting insurance use cases for each insurance company. To further explain the strategic relevance of an integrated perspective on the major technologies, Table 2 summarizes the interdependencies.

Table 2 shows that working with big data often requires artificial intelligence and that both technologies are highly interrelated as artificial intelligence can be categorized as a tool of big data analytics (e.g., EIOPA 2019). ${ }^{25}$ Moreover, the internet of things provides the base to generate a broad range of data, e.g., via connected cars or wearable devices. Employing big data is therefore necessary to further proceed, for instance, driving data to develop specific scores such as driving or claims scores (EIOPA 2019). Deriving a business strategy thus enforces the insurers to consider that implementing data analytics tools is one of the major requirements to translate informational content in the context of the internet of things to understandable results, to integrate them into the insurance products and to develop "smart" strategies in risk prediction and prevention (e.g., EIOPA 2019; Spender et al. 2019). ${ }^{26}$ In this context, cloud computing provides sufficient data storage capacity to efficiently operate the (new) methods of data analysis (e.g., EIOPA 2019; Kimmig 2020; Leroy et al. 2018). In addition to this, the distributed ledger technology with blockchain is discussed to increasingly support the implementation of other technologies by reducing their major weaknesses (e.g., Corea 2017).

However, developing a holistic digital strategy also includes a comprehensive assessment of limitations with regard to each approach and the interplay with further approaches. In general, the widespread adoption of digital applications depends on the pace of overcoming corresponding limitations. Major challenges are thereby presented regarding data privacy und data security of insureds or new risk categories (especially due to increasing connectivity). For instance, utilizing data in the context of the internet of things can be perceived as attack on the privacy of the policyholder (e.g., EIOPA 2019). While cloud computing can be applied to lower costs, collaborating with cloud computing providers as third parties also means new relationships of dependency (Wierse and Riedel 2017), and with blockchain being discussed as

\footnotetext{
24 According to Ketterer et al. (2016) $35 \%$ of the insurers' applications are legacy IT which is not compatible with cloud computing and again $35 \%$ of insurers rely on static HTML-based channels that are malfunctioning on mobile devices (Ketterer et al. 2016). Hence, $47 \%$ of insurance companies complain about a lack of integration and incompatibility (Poppleton et al. 2019).

25 BaFin (2018a) categorizes the interdependency between artificial intelligence and big data as an interplay between input (e.g., applying optical character creation), processes (e.g., operating natural language processing) and output (e.g., implementing robotic process automation).

${ }^{26}$ For instance, the virtual Amazon assistant Alexa provides support to the policyholders of an American insurer in case of hurricanes with the aim of damage prevention (BaFin 2018a).
} 


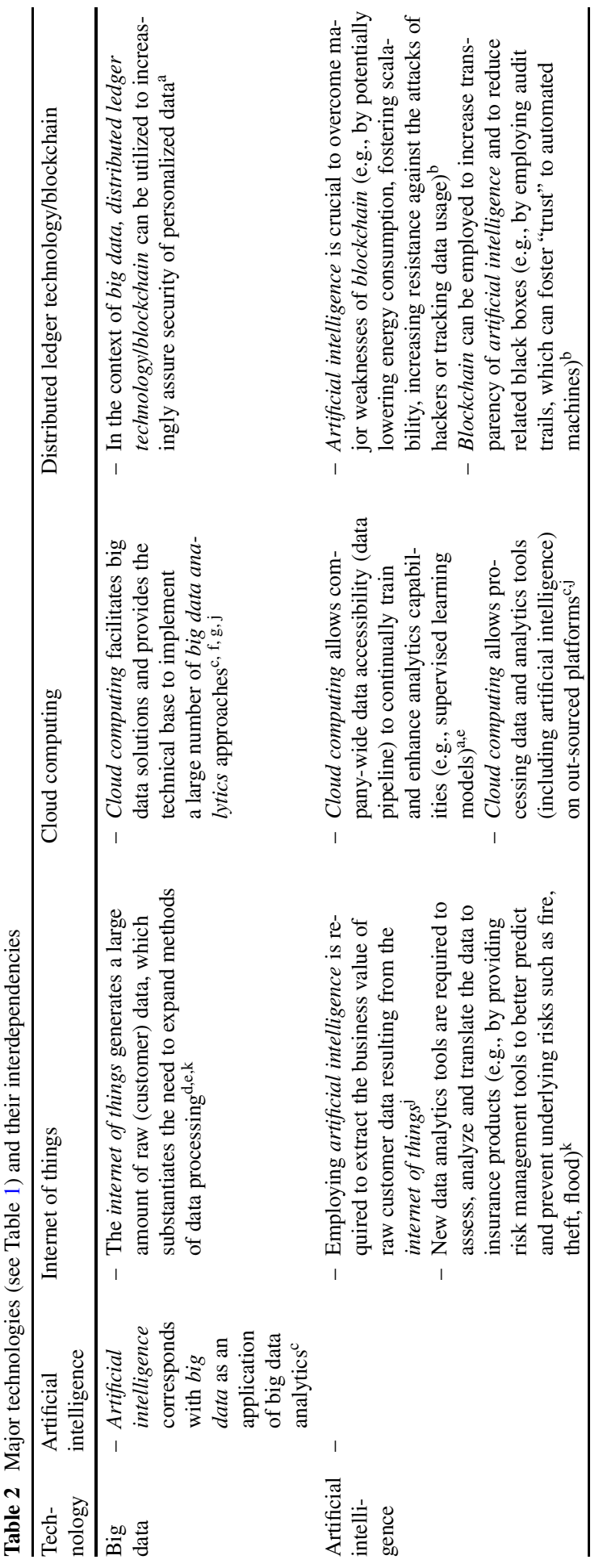




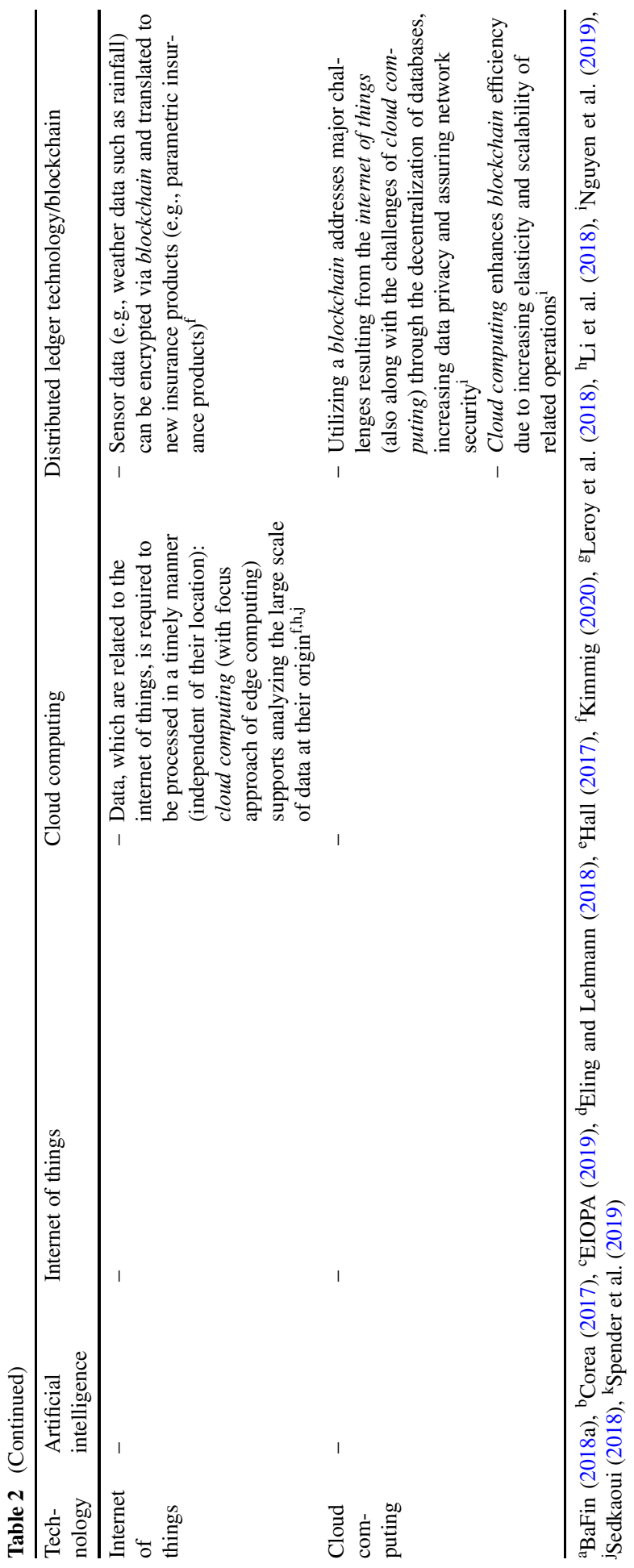


a forage-proof data carrier, it implies high costs that seem economically reasonable for only limited use cases (Brünnler 2018).

\section{Summary}

In this article, we analyze major digital technologies that are of high strategic relevance for the digital transformation of insurance companies. We also examine the impact of these technologies on the insurers' IT. Based on the data sample of the selected literature, we first describe and explain big data, artificial intelligence, the internet of things, cloud computing, and the distributed ledger technology as digital technologies. We further focus on the related benefits and opportunities for insurance companies along with the related insurance use cases.

Our results show that insurers are increasingly able to develop customer-centric products and services, e.g., by implementing enhanced customer segmentation and targeting methods or tailored underwriting and pricing. One major opportunity is the development of holistic insurance platforms consolidating prevention, (digital) consultancy, claims processing and risk prediction. Moreover, finding hidden patterns within large customer databases can contribute to reducing fraud. While we expect high investment to implement the approaches in the short term, the reviewed literature suggests that in the long term there are benefits regarding cost savings and a sharp rise in efficiency and effectivity. In particular, a major challenge is presented by amending or replacing legacy systems to meet the IT requirements for insurers to implement the major technologies.

However, our findings substantiate the claim that implementing the digital technologies with the insurance use cases requires an integrated strategic perspective due to the strong interdependencies of the digital technologies. This is not limited to a single digital technology. Given the high strategic relevance of reacting to digitalization, we specifically emphasize the increasing importance of holistically managing the IT of insurance companies that should be subject to further research.

Funding Open Access funding enabled and organized by Projekt DEAL.

Open Access This article is licensed under a Creative Commons Attribution 4.0 International License, which permits use, sharing, adaptation, distribution and reproduction in any medium or format, as long as you give appropriate credit to the original author(s) and the source, provide a link to the Creative Commons licence, and indicate if changes were made. The images or other third party material in this article are included in the article's Creative Commons licence, unless indicated otherwise in a credit line to the material. If material is not included in the article's Creative Commons licence and your intended use is not permitted by statutory regulation or exceeds the permitted use, you will need to obtain permission directly from the copyright holder. To view a copy of this licence, visit http://creativecommons.org/licenses/by/4. $0 /$.

\section{References}

Abdul-Kader, S.A., Woods, J.: Survey on chatbot design techniques in speech conversation systems. Int. J. Adv. Comput. Sci. Appl. 6(7), 72-80 (2015)

Albrecher, H., Bommier, A., Filipović, D., Koch-Medina, P., Loisel, S., Schmeiser, H.: Insurance: models, digitalization, and data science. Eur. Actuar. J. 9, 349-360 (2019) 
Ali, M., Kahn, S.U., Vasilakos, A.V.: Security in cloud computing: opportunities and challenges. Inform. Sci. 305, 357-383 (2015)

Anyoha, R.: The history of artificial intelligence (2017). http://sitn.hms.harvard.edu/flash/2017/historyartificial-intelligence/. Accessed 26 Aug 2020

BaFin: Big Data trifft auf künstliche Intelligenz (2018a). https://www.bafin.de/SharedDocs/Downloads/ DE/dl_bdai_studie.pdf?_blob=publicationFile\&v=3. Accessed 7 Mar 2020

BaFin: Cloud-Computing: Einhaltung der aufsichtsrechtlichen Vorgaben zu Informations- und Prüfungsrechten sowie Kontrollmöglichkeiten (2018b). https://www.bafin.de/SharedDocs/Veroeffentli chungen/DE/Fachartikel/2018/fa_bj_1804_Cloud_Computing.html. Accessed 19 Feb 2020

BaFin: Insurtech - Eine Einordnung. BaFin Journal (2019). https://www.bafin.de/SharedDocs/Veroeffent lichungen/DE/Fachartikel/2019/fa_bj_1901_Insurtech.html. Accessed 3 Mar 2020

Banafa, A.: IoT standardization and implementation challenges. IEEE Internet of Things Newsletter (2016). https://iot.ieee.org/newsletter/july-2016/iot-standardization-and-implementation-challenges. html. Accessed 26 Aug 2020

Baron, R., Chaudey, M.: Blockchain and smart-contract: a pioneering approach of inter-firms relationships? The case of franchise networks. Working Paper, University of Lyon (2019). https://ssrn.com/ abstract=3378477. Accessed 24 May 2019

Behm, S., Deetjen, U., Kaniyar, S., Methner, N., Münstermann, B.: Digital ecosystems for insurers: opportunities through the internet of things (2019). https://www.mckinsey.com/ /media/McKinsey/ Industries/Financial\%20Services/Our\%20Insights/Digital\%20ecosystems\%20for\%20insurers\%20 Opportunities $\% 20$ through $\% 20$ the $\% 20$ Internet $\% 20$ of $\% 20$ Things/Digital-ecosystems-for-insurersOpportunities-through-the-Internet-of-Things.ashx. Accessed 26 Jan 2020

Belanche, D., Casaló, L.V., Flavián, C.: Artificial intelligence in FinTech: understanding robo-advisors adoption among customers. Ind. Manag. Data Syst. 119(7), 1411-1430 (2019)

Berentsen, A., Schär, F.: Bitcoin, Blockchain und Kryptoassets: Eine umfassende Einführung. Books on Demand GmbH, Norderstedt (2017)

Bhowmik, R.: Detecting auto insurance fraud by data mining techniques. J. Emerg. Trends Comput. Inf. Sci. 2(4), 156-162 (2011)

Bitkom, KPMG: Mit Daten Werte schaffen (2016). https://cdn2.hubspot.net/hubfs/571339/LandingPagesPDF/kpmg-mdws-201-sec.pdf. Accessed 4 Aug 2020

Bohnert, A., Fritzsche, A., Gregor, S.: Digital agendas in the insurance industry: the importance of comprehensive approaches. Geneva Pap. Risk Insur. Issues Pract. 44(1), 1-19 (2019)

Bramblet, J., Presutti, D., Lyman, M., Starrs, A., Viale, E., Rangwala, A.: The post digital era is upon us (get ready for what's next in insurance) (2019). https://financialservices.accenture.com/rs/368-RMC-681/ images/Accenture-Technology-Vision-for-Insurance-2019-Full-Report.pdf. Accessed 29 Jan 2020

Brenner, M.: How to improve customer segmentation with AI (2019). https://marketinginsidergroup.com/ artificial-intelligence/how-to-improve-customer-segmentation-with-ai/. Accessed 30 Jan 2020

Brünnler, K.: Blockchain Kurz \& Gut. O’Reilly, Heidelberg (2018)

Burri, R.D., Burri, R., Bojja, R.R., Buruga, S.: Insurance claim analysis using machine learning algorithms. Int. J. Adv. Sci. Technol. 127(1), 147-155 (2019)

Capgemini: 5G in industrial operations (2019). https://www.capgemini.com/research/5g-in-industrialoperations/. Accessed 26 Jan 2020

Catlin, T., Hartmann, R., Segev, I., Tentis, R.: The making of a digital insurer: the path to enhanced profitability, lower costs and stronger customer loyalty (2015). http://www.mckinsey.com/industries/ financial-services/our-insights/the-making-of-a-digital-insurer. Accessed 12 Aug 2019

Corea, F.: The convergence of AI and blockchain: what's the deal? (2017). https://hackernoon.com/theconvergence-of-ai-and-blockchain-whats-the-deal-60c618e3accc. Accessed 3 Aug 2020

Dahuja, S.K.: Impact of technological advancements on general insurance. J. Insur. Inst. India 6(2), 47-55 (2019)

DalleMule, L., Davenport, T.H.: What's your data strategy. Harv. Bus. Rev. 95(3), 112-121 (2017)

Davidson, S., De Filippi, P., Potts, J.: Blockchains and the economic institutions of capitalism. J. Inst. Econ. 14(4), 639-658 (2018)

De Armond, C.: Deep learning has deep potential for insurers (2016). https://insuranceblog.accenture.com/ deep-learning-has-deep-potential-for-insurers. Accessed 22 Aug 2019

De Mauro, A., Greco, M., Grimaldi, M.: A formal definition of big data based on its essential features. Libr. Rev. 65(3), 122-135 (2016)

Deloitte: From mystery to mastery: unlocking the business value of artificial intelligence in the insurance industry (2017). https://www2.deloitte.com/content/dam/Deloitte/ie/Documents/Technology/ IE_Insurance\%20Whitepaper_0318.pdf. Accessed 27 Aug 2019 
Derikx, S., De Reuver, M., Kroesen, M.: Can privacy concerns for insurance of connected cars be compensated? Electron. Mark. 26(1), 73-81 (2016)

Desyllas, P., Sako, M.: Profiting from business model innovation: evidence from pay-as-you-drive auto insurance. Res Policy 42, 101-116 (2013)

Duncan, C., Dague, D., Giunta, S., Chandler, D., Schlieker, A.: Exploring cloud readiness in insurance (2019). https://www.accenture.com/us-en/insights/financial-services/tech-advisory-insurancecloud-strategic-investment-europe. Accessed 26 Jan 2020

Eckert, C., Eckert, J.: Maschinelles Lernen: Wie künstliche Intelligenz die Versicherungswirtschaft verändert. In: Eckstein, A., Funk-Münchmeyer, A., Liebetrau, A. (eds.) Insurance \& Innovation 2020: Ideen und Erfolgskonzepte von Experten aus der Praxis, pp. 87-93. Verlag Versicherungswirtschaft, Karlsruhe (2020)

EIOPA: Big data analytics in motor and health insurance: a thematic review (2019). https://www.eiopa. europa.eu/content/eiopa-reviews-use-big-data-analytics-motor-and-health-insurance_en. Accessed 24 Apr 2020

Eling, M., Lehmann, M.: The impact of digitalization on the insurance value chain and the insurability of risks. Geneva Pap. Risk Insur. Issues Pract. 43(3), 359-396 (2018)

Fang, K., Jiang, Y., Song, M.: Customer profitability forecasting using big data analytics: a case study of the insurance industry. Comput. Ind. Eng. 101, 554-564 (2016)

Foster, I., Ghani, R., Jarmin, R.S., Kreuter, F., Lane, J.: Big Data and Social Science (A Practical Guide to Methods and Tools). CRC Press, Boca Raton (2017)

Franke, U.: Towards increased transparency in digital insurance. ERCIM News (2019). https://ercim-news. ercim.eu/images/stories/EN116/EN116-web.pdf. Accessed 26 Aug 2020

Garde, M.D.: Fraud management in insurance claims. J. Insur. Inst. India IV(IV), 11-13 (2017)

Gatteschi, V., Lamberti, F., Demartini, C., Pranteda, C., Santamaria, V.: Blockchain and smart contracts for insurance: is the technology mature enough. Future Internet 10(2), 1-16 (2018)

Gatzert, N., Osterrieder, K.: The future of mobility and its impact on the automobile insurance industry. Risk Manag. Insur. Rev. 23(1), 31-51 (2020)

Gault, F.: Defining and measuring innovation in all sectors of economy. Res Policy 47(3), 617-622 (2018)

GDV: Versicherungscloud nach internationalen Sicherheitsstandards zertifiziert (2015). https://www. gdv.de/de/themen/news/versicherungscloud-nach-internationalen-sicherheitsstandards-zertifiziert16952. Accessed 7 Mar 2020

German Federal Government: Big Data und künstliche Intelligenz im Versicherungssektor (2018). http:// dip21.bundestag.de/dip21/btd/19/063/1906310.pdf. Accessed 30 Jan 2020

Grima, S., Spiteri, J., Romanova, I.: A STEEP framework analysis of the key factors impacting the use of blockchain technology in the insurance industry. Geneva Pap. Risk Insur. Issues Pract. 45, 398-425 (2020)

Gruhn, V.: Versicherungen: Von Natur aus für Künstliche Intelligenz geeignet. Wirtschaftsinform. Manag. 10(4), 104-111 (2018)

Hall, S.N.: How artificial intelligence is changing the insurance industry. CIPR newsletter (2017). https:// www.naic.org/cipr_newsletter_archive/vol22_ai.pdf. Accessed 26 Aug 2020

Hassan, A.K.I., Abraham, A.: Computational intelligence models for insurance fraud detection: a review of a decade of research. J. Netw. Innov. Comput. 1, 341-347 (2013)

Helfand, R.D.: Big data and insurance: what lawyers need to know and understand. J. Internet Law 21(3), 2-35 (2017)

Heo, W., Grable, J.E.: Demand for life insurance: a consumer perspective. Econ. Invest. Manag. 71(3), 19-22 (2017)

Hijazi, S., Kumar, R., Rowen, C.: Using convolutional neural networks for image recognition (2015). https://ip.cadence.com/uploads/901/cnn_wp-pdf. Accessed 26 Aug 2020

Hill, J., Ford, W.R., Farreras, I.G.: Real conversations with artificial intelligence: a comparison between human-human online conversations and human-chatbot conversations. Comput. Hum. Behav. 49, 245-250 (2015)

Huang, Y., Meng, S.: Automobile insurance classification ratemaking based on telematics driving data. Decis. Support Syst. 127, 113-156 (2019)

Jung, D., Dorner, V., Glaser, F., Morana, S.: Robo-advisory - digitalization and automation of financial advisory. Bus. Inf. Syst. Eng. 60(1), 81-86 (2018)

Kamble, S.S., Gunasekaran, A., Goswami, M., Manda, J.: A systematic perspective on the applications of big data analytics in healthcare management. Int. J. Healthc. Manag. 12(3), 226-240 (2019)

Karkouch, A., Mousannif, H., Al Moatassime, H., Noel, T.: Data quality in Internet of Things: a state-ofthe-art survey. J. Netw. Comput. Appl. 73, 57-81 (2016) 
Kelley, K.H., Fontanetta, L.M., Heintzman, M., Pereira, N.: Artificial intelligence: implications for social inflation and insurance. Risk Manag Insur Rev 21(3), 373-387 (2018)

Ketterer, H., Koopmans, J., Mäurers, R.: Building a digital technology foundation in insurance (2016). https://www.bcg.com/de-de/publications/2016/building-a-digital-technology-foundation-ininsurance.aspx. Accessed 26 Jan 2020

Kimmig, M.: Evolution statt Revolution: Zehn IT-Trends für die Assekuranz 2020 (2020). https:// versicherungswirtschaft-heute.de/maerkte-und-vertrieb/2020-01-13/evolution-statt-revolution-zehnit-trends-fuer-die-assekuranz-2020\%. Accessed 30 Jan 2020

Kotalakidis, N., Naujoks, H., Müller, F.: Digitalisierung der Versicherungswirtschaft: Die 18-MilliardenChance (2016). https://www.bain.com/contentassets/47d312fae3a94e9d9629c66d078243ab/baingoogle-studie_digitalisierung_der_versicherungswirtschaft_ds_final.pdf. Accessed 26 Aug 2019

Laney, D.: 3D data management: controlling data volume, velocity, and variety. META Group research note (2001). https://blogs.gartner.com/doug-laney/files/2012/01/ad949-3D-Data-ManagementControlling-Data-Volume-Velocity-and-Variety.pdf. Accessed 26 Aug 2020

Lehrer, C., Wieneke, A., Vom Brocke, J., Jung, R., Seidel, S.: How big data analytics enables service innovation: materiality, affordance, and the individualization of service. J. Manag. Inf. Syst. 35(2), 424-460 (2018)

Leroy, R., de Fontenay, E.B., Murugavel, K.: Insurance cloud - from tactical to strategic investment for European insurers (2018). https://www.accenture.com/_acnmedia/pdf-86/accenture-insurancecloud-strategic-investment-europe.pdf. Accessed 26 Jan 2020

Li, Z., Xiao, Z., Xu, Q., Sotthiwat, E., Goh, R.S.M., Liang, X.: Blockchain and IoT data analytics for finegrained transportation insurance. In: IEEE 224th Int. Conf. Parallel Distrib. Syst. pp. 1022-1027. (2018)

Lünendonk Study: Versicherungen in der Zeitfalle (2018). https://www.luenendonk.de/portfolio/versiche rungen-in-der-zeitfalle/. Accessed 21 Aug 2019

Maedche, A., Morana, S., Schacht, S., Werth, D., Krumeich, J.: Advanced user assistance systems. Bus Inf Syst Eng 58(5), 367-370 (2016)

Marinescu, D.C.: Cloud Computing (Theory and Practice). Morgan Kaufmann, Cambridge (2018)

Mathes, C.A.: Big data has unique needs for information governance and data quality. J. Manag. Sci. Bus. Intell. 1(1), 12-20 (2016)

Mell, P., Grance, T.: The NIST definition of cloud computing (2011). https://nvlpubs.nist.gov/nistpubs/ Legacy/SP/nistspecialpublication800-145.pdf. Accessed 27 July 2020

Nambisan, S., Wright, M., Feldman, M.: The digital transformation of innovation and entrepreneurship: progress, challenges and key themes. Res. Policy 48(8), 1-9 (2019)

Naujoks, H., Müller, F., Kotalakidis, N.: Digitalization in insurance: the multibillion dollar opportunity (2017). https://www.bain.com/insights/digitalization-in-insurance/. Accessed 11 Aug 2019

Nguyen, D.C., Pathirana, P.N., Ding, M., Seneviratne, A.: Integration of blockchain and cloud of things: architecture, applications and challenges (2019). https://arxiv.org/abs/1908.09058. Accessed 8 Aug 2020

Owadally, I., Zhou, F., Otunba, R., Lin, J., Wright, D.: Time series data mining with an application to measure of underwriting cycles. N. Am. Actuar. J. 23(3), 469-484 (2019)

Poppleton, A., Struntz, J., Lees, C.: Get comfortable outside your comfort zone (2019). https://www. accenture.com/_acnmedia/pdf-92/accenture-insurance-digital-transformation-remaking-an-industry. pdf. Accessed 26 Jan 2020

Pritchett, W., Terry, H., Makita, Y., Brenchley, P., Adesman, I., Milligan, D., Huang, B., Plotkin, G.: Insurtech 10: trends for 2019 (2019). https://assets.kpmg/content/dam/kpmg/mu/pdf/2019/insurtechtrends-2019.pdf. Accessed 4 Aug 2020

Priyadarshini, S.B.B., BhusanBagjadab, A., Mishra, B.K.: The role of IoT and big data in modern technological arena: a comprehensive study. In: Balas, V.E., Solanki, V.K., Kumar, R., Khari, M. (eds.) Internet of Things and Big Data Analytics for Smart Generation, pp. 13-25. Springer, Cham (2019)

Pusala, M.K., Salehi, M.A., Katukuri, J.R., Xie, Y., Raghavan, V.: Massive data analysis: tasks, tools, applications, and challenges. In: Pyne, S., Rao, B.P., Rao, S.B. (eds.) Big Data Analytics, pp. 11-40. Springer, New Delhi (2016)

PwC: Blockchain in Financial Services - Mehr als nur ein Hype? (2018). https://www.pwc.de/de/ finanzdienstleistungen/Blockchain_in_Financial_Services_2018.pdf. Accessed 30 Jan 2020

Ravi, V., Kamaruddin, S.: Big data analytics enabled smart financial services: opportunities and challenges. In: Reddy, P.K., Sureka, A., Chakravarthy, S., Bhalla, S. (eds.) Big Data Analytics, pp. 15-39. Springer, Cham (2017) 
Riikkinen, M., Saarijärvi, H., Sarlin, P., Lähteenmäki, I.: Using artificial intelligence to create value in insurance. Int. J. Bank Mark. 36(6), 1145-1168 (2018)

Russell, S., Norvig, P.: Artificial intelligence: a modern approach. Prentice Hall, Upper Saddle River (2016)

SCOR: The impact of artificial intelligence on the (re)insurance sector (2018). https://www.scor.com/sites/ default/files/focus_scor-artificial_intelligence.pdf. Accessed 29 Jan 2020

Sedkaoui, S.: Data Analytics and Big Data. John Wiley \& Sons, New York (2018)

Shang, K.: Applying image recognition to insurance. Society of Actuaries (2018). https://www.soa.org/ globalassets/assets/Files/resources/research-report/2018/applying-image-recognition.pdf. Accessed 26 July 2020

Sheth, A., Subramanian, H.: Blockchain and contract theory: modeling smart contracts using insurance markets. Manag. Financ. (2019). https://doi.org/10.1108/MF-10-2018-0510

Singer, A.W.: Can blockchain improve insurance? Risk Manag. 66(1), 20-25 (2019)

Sironi, P.: FinTech Innovation: From Robo-Advisors to Goal Based Investing and Gamification. John Wiley \& Sons, Chichester (2016)

Sivarajah, U., Kamal, M.M., Irani, Z., Weerakkody, V.: Critical analysis of big data challenges and analytical methods. J Bus Res 70, 263-286 (2017)

Solanki, V.K., Makkar, S., Kumar, R., Chatterjee, J.M.: Theoretical analysis of big data for smart scenarios. In: Balas, V.E., Solanki, V.K., Kumar, R., Khari, M. (eds.) Internet of Things and Big Data Analytics for Smart Generation, pp. 1-12. Springer, Cham (2019)

Soni, M.: End to end automation on cloud with build pipeline: the case for DevOps in insurance industry, continous integration, continous testing, and continous delivery. In: IEEE Int. Conf. Cloud Comput. Emerg. Mark. pp. 85-89. (2015)

Spender, A., Bullen, C., Altmann-Richer, L., Cripps, J., Duffy, R., Falkous, C., Farrell, M., Horn, T., Wigzell, J., Yeap, W.: Wearables and the internet of things: considerations for the life and health insurance industry. Br. Actuar. J. 24(22), 1-31 (2019)

Spichale, K.: API-Design: Praxishandbuch für Java- und Webservice-Entwickler. dpunkt, Heidelberg (2017)

Stein, B., Morrison, A.: The enterprise data lake: better integration and deeper analytics. PwC technology forecast: rethinking integration (2014). https://www.pwc.com/us/en/technology-forecast/2014/cloudcomputing/assets/pdf/pwc-technology-forecast-data-lakes.pdf. Accessed 5 Aug 2020

Taleb, I., Serhani, M.A., Dssouli, R.: Big data quality assessment model for unstructured data. In: 13th Int. Conf. Innov. Inf. Technol. pp. 69-74. (2018)

Tarr, J.A.: Distributed ledger technology, blockchain and insurance: opportunities, risk, and challenges. Insur. Law J. 29, 254-268 (2018)

Ur Rehman, M.H., Chang, V., Batool, A., Wah, T.Y.: Big data reduction framework for value creation in sustainable enterprises. Int. J. Inf. Manag. 36(6), 917-928 (2016)

Urbach, N., Ahlemann, F.: IT-Management im Zeitalter der Digitalisierung. Springer, Berlin (2016)

Venkatesh, S.: Big data - Can it make a big impact in the insurance sector? J. Insur. Inst. India VI(IV), 92-97 (2019)

Vesset, D.: Descriptive analytics 101: what happened? (2018). https://www.ibm.com/blogs/businessanalytics/descriptive-analytics-101-what-happened/. Accessed 25 Aug 2019

Wibowo, M., Sarina, S., Siti, M.S.: Machine learning in data lake for combining data silos. In: Int. Conf. Data Min. Big Data, pp. 294-306. (2017)

Wierse, A., Riedel, T.: Smart Data Analytics: Zusammenhänge erkennen, Potenziale nutzen, Big Data verstehen. De Gruyter, Berlin (2017)

Zhang, X.F., Xu, Z.S., Ren, P.J.: A novel hybrid correlation measure for probablistic linguistic term sets and crisp numbers and its application in customer relationship management. Int. J. Inf. Technol. Decis. Mak. 18(2), 673-694 (2019)

Zies, I., Schmid, U.: Mehr Tempo, weniger Altlasten: IT-Architektur im digitalen Zeitalter (2016). https:// www.bain.com/de/insights/more-speed-fewer-legacies-it-architecture-in-the-digital-age/. Accessed 26 Jan 2020 